IRSTI 29.27.51

\title{
Plasma methods for toxic wastes processing
}

\author{
A.L. Mosse ${ }^{*}$ and A.B. Ustimenko \\ Heat and Transfer Institute, 15 P, Brovka str., 220072, Minsk, Belarusia \\ *e-mail:mosse@itmo.by
}

\begin{abstract}
Pollution of the environment with production waste is one of the most acute problems in the industrialized countries. Many of the accumulated waste have the properties of toxicity, mutagenicity, carcinogenicity, fire hazard and can affect both the health of the population in the regions where they are stored, and lead to the emergence of global environmental emergencies. Traditional technologies for the destruction of toxic waste in various thermal installations are characterized by a relatively low process temperature. In the product remaining after processing, a significant quantity of primary and secondary pollutants formed in the process of processing may be present in concentrations above the maximum permissible levels. The development of new methods for the processing and destruction of toxic waste is one of the most urgent scientific and technical problems, the practical importance of which is undeniable. The use of thermal plasma for the destruction of toxic wastes makes it possible to increase the minimum combustion / pyrolysis temperature in the reaction zone of the reactor to $2000 \mathrm{~K}$ and above, thereby eliminating the course in the gas phase of the reaction with the formation of highly toxic compounds: phosgene, dioxins, polyhalogenated biphenyls and furans. Experimental study of thermal neutralization of some toxic chlorine and bromine industrial wastes, as well as of pesticides with an expired term of validity was carried out in the three-jet plasma reactor. Different physical-chemical methods were used for analysis of products of waste processing. It was shown that plasma technology provides effective processing of toxic wastes.
\end{abstract}

Key words: toxic waste, plasma processing, fuel gas, experiment.

PACS number(s): 44.35.+c; 51.10.+y; 52.77.-j; 82.20.-w

\section{Introduction}

Alternative to conventional low-temperature methods of toxic wastes incineration is their destruction in thermal plasma, which takes place at high temperature. Using arc and other plasmas delivering temperature of the order of $5000 \mathrm{~K}$ makes possible to break down organic and nonorganic compounds in plasma is highly effective even without oxygen. The other merit is possibility of good mixing in plasma chemical reactor, this is the important factor of wastes thermal processing. This process can be realized in the multi-jet plasma reactor which provides good mixing of plasma with treated wastes [1-6]. The plasma reactor including three-jet mixing chamber with attached three plasma torches. The installation contains a system of raw material supply into the plasma reactor. A system of stub tube, vacuum pump and a set of evacuated flasks was used to extract exhaust gas for analysis. There were also units for power and water supply, for arc ignition and for control system of work parameters of the installation. The system works on the following principle: interaction between three intakes plasma jets and wastes produces in the mixing chamber a certain heterophase flow which then forms the reaction zone over the whole length of the reactor dust. The physical-chemical processes of wastes thermal destruction take course just in this reactor and separation of the power products takes place then in a hopper whereas gases are conveyed into special filter to remove ultradispersed fractions. Gases pass then through a lye scrubber and are exhausted into atmosphere by a fan.

\section{Processing and destruction of chloroorganic wastes}

Decomposition (destruction) products of the real withdrawals were analyzed. The withdrawals were the mixture of the following products; trichloroethylene - $80 \%$, nitrotoluene - $17 \%$, nitrobenzoalcohol - 1,1\%, nitrobenzoaldehyde $1,1 \%$, carbon tetrachloride - 0,8\%. Toxic connections were not established in the composition of exiting products [7-12].

All experimental investigations were made with a constant waste feed of $3.6 \mathrm{~kg} / \mathrm{h}$. The variation of the plasma air supply was connected with a corresponding change of the carbon-oxigen-ratio in 
the plasma reactor. On the other side the increase of the plasma generator. Due to the realized air supply the waste conversion was happen in all cases in a reduction atmosphere. In agreement with the calculation of the thermodynamic equilibrium the analysis of the gas phase shows a complete conversion of the organic substance into carbon monoxide and hydrogen respectively carbon dioxide and stream. Each sample contained hydrogen chloride and hydrogen sulfide in small concentrations. Free chlorine was not be detected. The gaseous phase was analyzed by means of gas chromatography and the mass-spectrometer MAT 311 Varian.

In some cases the product gas contained a insignificant amount of soot which points out that locally a pyrolysis regime took place. The formation of soot could be stopped by supply secondary air at the end of the reactor. In all experiments in gas phase a small concentration of nitrogen oxides was found, although in the thermodynamic calculations it occurred only in oxygenous atmosphere. This fact may be connected with the formation of the oxides in the plasma jet and the short reaction time prevented the decomposition.

\section{Processing and destruction of bromine containing waste}

Study was done with the solid free-flowing wastes containing bromide phenols with different proportions. Elemental analysis of the wastes was made by different methods before experiments. The average results obtained by different methods are: $\mathrm{C}=30.03 \% ; \quad \mathrm{H}_{2}=4.31 \% ; \quad \mathrm{Br}=50.32 \% ; \quad \mathrm{N}_{2}=0.51 \%$; $\mathrm{S}=0.08 \% ; \quad \mathrm{O}_{2}=14.75 \%$. The previous thermal analysis was also used for bromide-phenol wastes [13-16].

Water solution of $2.5 \%$ bromine mass was prepared for the first run of bromine wastes. It was expedient for the sake of monitoring disperse solution feed into the plasma heat medium at the high concentration of material. The run of experiments with this solution was carried out at variation of power and material feeding rate. Consumed electric power ranged over $95-120 \mathrm{~kW}$, plasma forming gas flow rate accounted for $4.7 \mathrm{~g} / \mathrm{s}$, and material supply varied from 1.0 to $15.5 \mathrm{~g} / \mathrm{s}$. The degree of decomposition amended to $100 \%$ for all experiments of the run. Chemical analysis of exhausting gases for content of bromine and toxic components was made after every experiment. No toxic dioxin and oxide was detected.
Possibility to increase the efficiency of the process at the expense of the solution doping was investigated at the second run of experiments. Three experiments, with the $75 \%$ solution of wastes in a polar organic solvent were made for processing optimization. At this run, electric power varied from 80 to $110 \mathrm{~kW}$, material rate ranged over $5.6-12.5$ $\mathrm{g} / \mathrm{s}$, and flow rate of the working gas was taken at the constant level $6.0 \mathrm{~g} / \mathrm{s}$. The complete decomposition was observed at maximal material rate, but the incineration was incomplete and a lot of unoxidized carbon was settled out in the wateralkaline scrubber. Exhausting gases produced during the plasma chemical processing of the wastes were analyzed for the content of dioxides and their analogues, carbon oxides and dioxides, as well as for concentration of bromine hydrogen. Massspectrometer Hewlet-Packard GC/MS 5890/5972 was used for analysis of dioxides applying EPA 8270 method with gas filtration through methanol and the subsequent examination of methanol solution. All experiments exhibit no dioxide. Content of $\mathrm{CO}$ was analyzed by mass-spectrometer MX-1320 with high resolution. The observed $\mathrm{m} / \mathrm{z}$ 29 peak had intensity $0.8 \%$ that indicates the absent of $\mathrm{CO}$ in the gaseous phase. As to content of oxygen, it was found to be low in the first experimental run and negligible in the second one. On the other hand, the measurements demonstrated high concentration of nitrogen. Proportion of HBR in the produced gaseous mixture was measured by gravimetric chemical-analytical method with titration of $\mathrm{HBr}$ by silver nitride solution and subsequent analysis of silver bromide by massspectrometry. The concentration of $\mathrm{HBr}$ in the gaseous phase at normal conditions was determined both runs: for optimal experiment of the first run upstream from scrubber $-0.337 \mathrm{~g} / 1$ and downstream of it $-0.143 \mathrm{~g} / \mathrm{l}$; for optimal experiment of the second run upstream from scrubber $-0.03 \mathrm{~g} / \mathrm{l}$ and downstream of it $-0.015 \mathrm{~g} / \mathrm{l}$.

The component $\mathrm{HBr}$ can be considered as a useful desired product of such a wastes processing that can be used for pure bromine production. The experiments have shown that the yield of $\mathrm{HBr}$ in the first run applying water-emulsion feed of the wastes is about an order higher then in the second run when organic solvent was used and the plasma-chemical process proceeded at the excess of free carbon and deficient air. Bromine vaporization and reduction at the excess of $\mathrm{H}_{2} \mathrm{O}$ according to the first variant is apparently the most efficient method of the wastes processing. 


\section{Processing and destruction of pesticides with a expired term of validity.}

Investigations are carried out in different regimes of the work of plasma reactor for processing of two pesticides - isophene $\left(\mathrm{C}_{14} \mathrm{H}_{18} \mathrm{O}_{7} \mathrm{~N}_{2}\right)$ and concentrate of butyl ether of 2,4dichlorphenoacetic acid $\left(\mathrm{C}_{4} \mathrm{H}_{9} \mathrm{CH}_{2} \mathrm{COOC}_{6} \mathrm{H}_{3} \mathrm{Cl}_{2}\right)$, with expired term of validity. Both these pesticides consist of 50-60\% of base material (butyl ether and isophene) and 50-40\% of the filler substances, which contains of kaolin, aerosol and silica gel. The detailed analysis of gases at the outlet of plasma reactor is executed. The methods of chromatomass-spectrometry and absorption spectroscopy in ultraviolet (UVR), visible and infrared (IR) wavelength range are used [17-20].

Absorption spectra in the UVR, visible and near IR wavelength range $(0.2-3,0 \mu \mathrm{m})$ were recorded with UV- Vis -NIR- spectrophotometer " Cary 500 Scan" of the firm " Varian " (USA), in such spectra in the distant IR area $(2,5-25 \mu \mathrm{m})$ - were detected by Furie spectrometer " IFS28 " of the firm " Brucker" (Germany).

The analysis of the obtained spectrograms made it possible to establish that they weakly depend qualitatively on the type of the raw material used and are presented by three characteristic absorption bands: $\Delta \lambda=0.2|0.25 \mu \mathrm{m}, \Delta \lambda=0.35| 0.6 \mu \mathrm{m}$, and $\Delta \lambda=2.5 \mid 25 \mu \mathrm{m}$. Because of the high optical density of mixture in the UVR region of the spectrum we could not interpret reliably the recorded maximums of absorption. They can be the diffuse absorption bands of hydrocarbons of the type of the benzaldehyde $\mathrm{C}_{6} \mathrm{H}_{5} \mathrm{CHO}$ of the propionaldegida $\mathrm{C}_{2} \mathrm{H}_{5} \mathrm{CHO}$, benzene $\mathrm{C}_{6} \mathrm{H}_{6}$, formaldehyde $\mathrm{CH}_{2} \mathrm{O}$, acetaldehyde $\mathrm{C}_{2} \mathrm{H}_{4} \mathrm{O}$, etc. with transitive into the intensive continuum.

The visible region of the spectrum is presented by the electron- vibrational-rotational absorption bands of molecules $\mathrm{NO}, \mathrm{NO}_{2}, \mathrm{HNO}_{2}, \mathrm{O}_{2}, \mathrm{CO}_{2}, \mathrm{C}_{2}$, $\mathrm{AlO}, \mathrm{AlH}, \mathrm{HfO}, \mathrm{CaO}, \mathrm{FeO}, \mathrm{CuO}, \mathrm{CuH}, \mathrm{CN}, \mathrm{SiN}$, $\mathrm{CH}, \mathrm{CHO}$. However we could not identified a number of the maximums of absorption as well as in the spectrograms of UVR range. In the absorption spectra in the IR region we discovered the bands $\mathrm{CH}_{3-}, \mathrm{CH}_{2-}, \mathrm{CH}-$ of the groups of hydrocarbons and $\mathrm{NO}_{3}$ - group, bands $\mathrm{CO}_{2}, \mathrm{H}_{2} \mathrm{O}, \mathrm{N}_{2}, \mathrm{NO}_{2}$, the traces of bands $\mathrm{NO}$, bands of the condensed phase $\mathrm{HNO}_{3}$, of the vapor phase $\mathrm{H}_{2} \mathrm{CO}_{3}$, the bands of the valency oscillation of the carbonyl group $\mathrm{C}=\mathrm{O}$, and also the weakly intensive bands of the deformation oscillations $\mathrm{OH}$ and $\mathrm{CO}$.
Obtained data testify about the intensive thermal decomposition of pesticides in the plasma airflow, which is accompanied by oxidation and nitriding of the products of decomposition. Bands $\mathrm{CH}_{3-}, \mathrm{CH}_{2-}$, $\mathrm{CH}-$, and $\mathrm{C}=\mathrm{O}$ groups are caused by the formation of the secondary hydrocarbons at the outlet of the plasma reactor in hardening zone. Formed simple oxides and nitrides are not highly toxic or cancerogenic substances and are not ecologically dangerous. Some of them can be separated, assembled and used further.

Chromato-mass-spectrometric analysis of emanated gases was performed for a determination of a type of produced hydrocarbons and their quantitative content in the outlet of plasma reactor. Chromato-mass-spectrometer "MM" of "Brucker" firm (Germany) was use4. Processing and destruction of pesticides with a expired term of validity.

Investigations are carried out in different regimes of the work of plasma reactor for processing of two pesticides - isophene $\left(\mathrm{C}_{14} \mathrm{H}_{18} \mathrm{O}_{7} \mathrm{~N}_{2}\right)$ and concentrate of butyl ether of 2,4dichlorphenoacetic acid $\left(\mathrm{C}_{4} \mathrm{H}_{9} \mathrm{CH}_{2} \mathrm{COOC}_{6} \mathrm{H}_{3} \mathrm{Cl}_{2}\right)$, with expired term of validity. Both these pesticides consist of 50-60\% of base material (butyl ether and isophene) and 50-40\% of the filler substances, which contains of kaolin, aerosil and silica gel. The detailed analysis of gases at the outlet of plasma reactor is executed. The methods of chromatomass-spectrometry and absorption spectroscopy in ultraviolet (UVR), visible and infrared (IR) wavelength range are used.

Spectra in the UVR, visible and near IR wavelength range $(0.2-3.0 \mu \mathrm{m})$ were recorded with UV- Vis -NIR- spectrophotometer " Cary 500 Scan“" of the firm " Varian " (USA), in such spectra in the distant IR area $(2.5-25 \mu \mathrm{m})$ - were detected by Furie spectrometer " IFS28 " of the firm " Brucker" (Germany). The analysis of the obtained spectrograms made it possible to establish that they weakly depend qualitatively on the type of the raw material used and are presented by three characteristic absorption bands: $\Delta \lambda=0.2 \mid 0.25 \mu \mathrm{m}$, $\Delta \lambda=0.35 \mid 0.6 \mu \mathrm{m}$, and $\Delta \lambda=2.5 \mid 25 \mu \mathrm{m}$. Because of the high optical density of mixture in the UVR region of the spectrum we could not interpret reliably the recorded maximums of absorption. They can be the diffuse absorption bands of hydrocarbons of the type of the benzaldehyde $\mathrm{C}_{6} \mathrm{H}_{5} \mathrm{CHO}$ of the propionaldegida $\mathrm{C}_{2} \mathrm{H}_{5} \mathrm{CHO}$, benzene $\mathrm{C}_{6} \mathrm{H}_{6}$, formaldehyde $\mathrm{CH}_{2} \mathrm{O}$, acetaldehyde $\mathrm{C}_{2} \mathrm{H}_{4} \mathrm{O}$, etc. with transitive into the intensive continuum. The visible 
region of the spectrum is presented by the electronvibrational-rotational absorption bands of molecules $\mathrm{NO}, \mathrm{NO}_{2}, \mathrm{HNO}_{2}, \mathrm{O}_{2}, \mathrm{CO}_{2}, \mathrm{C}_{2}, \mathrm{AlO}, \mathrm{AlH}, \mathrm{HfO}$, $\mathrm{CaO}, \mathrm{FeO}, \mathrm{CuO}, \mathrm{CuH}, \mathrm{CN}, \mathrm{SiN}, \mathrm{CH}, \mathrm{CHO}$. However we could not identified a number of the maximums of absorption as well as in the spectrograms of UVR range.

In the absorption spectra in the IR region we discovered the bands $\mathrm{CH}_{3}-, \mathrm{CH}_{2^{-}}, \mathrm{CH}-$ of the groups of hydrocarbons and $\mathrm{NO}_{3}$ - group, bands $\mathrm{CO}_{2}, \mathrm{H}_{2} \mathrm{O}$, $\mathrm{N}_{2}, \mathrm{NO}_{2}$, the traces of bands $\mathrm{NO}$, bands of the condensed phase $\mathrm{HNO}_{3}$, of the vapor phase $\mathrm{H}_{2} \mathrm{CO}_{3}$, the bands of the valency oscillation of the carbonyl group $\mathrm{C}=\mathrm{O}$, and also the weakly intensive bands of the deformation oscillations $\mathrm{OH}$ and $\mathrm{CO}$.

Obtained data testify about the intensive thermal decomposition of pesticides in the plasma airflow, which is accompanied by oxidation and nitriding of the products of decomposition. Bands $\mathrm{CH}_{3}-, \mathrm{CH}_{2-}$, $\mathrm{CH}$-, and $\mathrm{C}=\mathrm{O}$ groups are caused by the formation of the secondary hydrocarbons at the outlet of the plasma reactor in hardening zone. Formed simple oxides and nitrides are not highly toxic or carcinogenic substances and are not ecologically dangerous. Some of them can be separated, assembled and used further.

Chromato-mass-spectrometric analysis of emanated gases was performed for a determination of a type of produced hydrocarbons and their quantitative content in the outlet of plasma reactor. Chromato-mass-spectrometer "MM" of "Brucker" firm (Germany) was used, range of mass numbers was 28-400, resolving power $\mathrm{R}$ was $\sim 10000$, threshold of detectability was $\sim 1$ ppb $\left(\sim 10^{-3}\right)$. Samples were taken after hardening zone with help of program pump SKS and were placed at two-layer absorb tubes of the firm "Dreger". Activated coal was used as absorb substance. Duration of sample taking was $4 \mathrm{~min}$, velocity of pumping (circulation rate) of samples trough sorbents was $300 \mathrm{l} / \mathrm{min}$. Preliminary separation of mixture components was curried out at the capillary column. Quadrupole mass-analyzer was used as a mass-detector. Produced products were identified by the comparison of complete mass-spectrum of analyzed substance or of its separate peaks with mass-spectra from the bank of standard substances. In order to increase statistic significance of the identification we used two methods of library search: a straight one, which provides computer comparison of analyzed spectrum with each library spectrum consequently, and a reverse method, which provides comparison of library spectra consequently with analyzed one. For a calculation of every component concentration an evaluation of absorb substance mass and data of normalization of chromatometry results were used. Instrumental error of an evaluation of different substance contents in analyzed gases mixture was less $30-40 \%$.

Results of tests in the experiments with isophene and butyl ether processing are presented in tables 1 and 2. After butyl ether processing without hardening we found saturated, unsaturated and aromatic hydrocarbons, ordinary and complicated ethers, alcohols, ketones, acids nitrogencontaining and chlorcontaining compounds in the products leaving plasma reactor. In the experiments plasmaforming gas was technical air. Average value of the specific enthalpy of plasma along the length of the reactor was about $6000 \mathrm{~kJ} / \mathrm{kg}$.

Table 1 - Results of the chromato-mass-pectrometric analysis of the composition of waste gas during the plasmachemical processing of pesticides on the basis of isophene $\mathrm{C}_{14} \mathrm{H}_{18} \mathrm{O}_{7} \mathrm{~N}_{2}$

\begin{tabular}{|c|c|c|}
\hline Designation of the substance & The chemical formula & Concentration in the waste gas flow, mg/l \\
\cline { 2 - 3 } & & With the charge of raw material, with the hardening \\
\hline Methyl nitrate, & & \\
1,3 propandioldinitrat, & $\mathrm{CH}_{3} \mathrm{NO}_{3}$ & \\
\hline 1,3 propenediol & $\mathrm{C}_{3} \mathrm{H}_{6} \mathrm{~N}_{2} \mathrm{O}_{6}$ \\
$\mathrm{C}_{4} \mathrm{H}_{6} \mathrm{~N}_{4} \mathrm{O}_{11}$ & \\
\hline 3-heptanone & $\mathrm{C}_{7} \mathrm{H}_{14} \mathrm{O}$ & 0.17 \\
\hline Isoamyl nitrite & $\mathrm{C}_{5} \mathrm{H}_{11} \mathrm{NO}_{2}$ & 0.06 \\
\hline 2-propyl-1- pentanol & $\mathrm{C}_{8} \mathrm{H}_{18} \mathrm{O}$ & 0.59 \\
\hline 3,5,5-trimethylhexanol & $\mathrm{C}_{9} \mathrm{H}_{20} \mathrm{O}$ & 0.04 \\
\hline 3,5-dimethyloctane & $\mathrm{C}_{10} \mathrm{H}_{22}$ & 0.04 \\
\hline Undecane & $\mathrm{C}_{11} \mathrm{H}_{24}$ & 0.09 \\
\hline 2,2-dimethyl-3-hexanol & $\mathrm{C}_{8} \mathrm{H}_{18} \mathrm{O}$ & 0.71 \\
\hline
\end{tabular}


As Tables 1 and 2 show, a hardening changes significantly the composition of reactor off-gases. Clorcontaining and nitrogencontaining compounds, as well as some substances which contain ether groups and aldehyde groups were not detected at the outlet of reactor. Benzol derivations appear instead of them. Absence of compounds with ether groups and aldehyde ones and content increasing of compounds of types of methylcellosolve and benzoic acid can be caused by processes of secondary oxidation in the zone of hardening.

Nitrogen containing substances can be performed in the presence of hydrogen into nitroacid or nitrozoacid, they was proved by the spectroscopy analysis. Chlorcontaining compounds can be performed in presence of chlorine salt at the base of calcium, copper and iron, they was detected also by spectroscopy method.

Table 2 - Results of the chromato-mass-pectrometric analysis of the composition of waste gas during the plasmachemical processing of pesticides on the basis of r- butyl ether $\mathrm{C}_{4} \mathrm{H}_{9} \mathrm{CH}_{2} \mathrm{COOC}_{6} \mathrm{H}_{3} \mathrm{CL}_{2}$

\begin{tabular}{|c|c|c|c|c|}
\hline \multirow[t]{2}{*}{ Designation of the substance } & \multirow[t]{2}{*}{ The chemical formula } & \multicolumn{3}{|c|}{ Concentration in the waste gas flow, $\mathrm{mg} / \mathrm{l}$} \\
\hline & & $\begin{array}{l}\text { With the charge of } \\
\text { raw material, without } \\
\text { the hardening }\end{array}$ & $\begin{array}{l}\text { With the charge of } \\
\text { raw material, with } \\
\text { the hardening }\end{array}$ & $\begin{array}{l}\text { Without the raw } \\
\text { material, without } \\
\text { the hardening }\end{array}$ \\
\hline Methyl cellosolve & $\mathrm{C}_{3} \mathrm{H}_{8} \mathrm{O}_{2}$ & 0.63 & 3.01 & 1.18 \\
\hline Diisopropyl ether & $\mathrm{C}_{6} \mathrm{H}_{10} \mathrm{O}$ & 3.08 & - & 6.86 \\
\hline Heptanone, 3 & $\mathrm{C}_{7} \mathrm{H}_{14} \mathrm{O}$ & 0.44 & - & - \\
\hline Hexanol, 2-ethyl & $\mathrm{C}_{8} \mathrm{H}_{16} \mathrm{O}$ & 1.64 & - & - \\
\hline Heptene $1 / 3$ & $\mathrm{C}_{7} \mathrm{H}_{14}$ & 2.24 & 5.1 & - \\
\hline Butylisocyanate & $\mathrm{C}_{5} \mathrm{H}_{9} \mathrm{NO}$ & 2.61 & - & - \\
\hline 2-nitrophenol & $\mathrm{C}_{6} \mathrm{H}_{5} \mathrm{NO}_{3}$ & 0.78 & - & - \\
\hline Acetophenone & $\mathrm{C}_{8} \mathrm{H}_{8} \mathrm{O}$ & 2.68 & - & 1.88 \\
\hline Benzoic acid & $\mathrm{C}_{7} \mathrm{H}_{6} \mathrm{O}_{2}$ & 5.12 & 6.76 & 7.30 \\
\hline Benzophenone & $\mathrm{C}_{13} \mathrm{H}_{10} \mathrm{O}$ & 0.91 & 3.29 & 4.03 \\
\hline Acetophenone, 8-chloro & $\mathrm{C}_{8} \mathrm{H}_{7} \mathrm{ClO}$ & 4.35 & - & 6.13 \\
\hline Heptachlorepoxide & $\mathrm{C}_{10} \mathrm{H}_{5} \mathrm{Cl}_{7} \mathrm{O}$ & 3.28 & - & - \\
\hline Xylene & $\mathrm{C}_{8} \mathrm{H}_{10}$ & - & 0.15 & - \\
\hline Benzene trimethyl & $\mathrm{C}_{9} \mathrm{H}_{12}$ & - & 0.09 & - \\
\hline Undecane, dodecane, tridecane & $\begin{array}{c}\mathrm{C}_{11} \mathrm{H}_{24}, \mathrm{C}_{12} \mathrm{H}_{26} \\
\mathrm{C}_{13} \mathrm{H}_{28}\end{array}$ & - & 0.13 & \\
\hline Butanol, ethyl & $\mathrm{C}_{6} \mathrm{H}_{14} \mathrm{O}$ & - & - & 2.92 \\
\hline Isobutylacetate & $\mathrm{C}_{6} \mathrm{H}_{12} \mathrm{O}_{2}$ & - & - & 0.15 \\
\hline
\end{tabular}

\section{Conclusions}

1. To process toxic waste of various origin, a plasma reactor with a three-jet mixing chamber was designed and tested. Three electric arc plasma torches operate for it. The impact of three plasma jets is directed to the jet of waste, which contributes to a better mixing of waste and coolant. Such mixing allows a continuous and continuous supply of a dust-gas or liquid jet of waste in the form of an emulsion or suspension, when their increased concentration is compensated by low toxicity. In this way, as shown experimentally, it is possible to feed and process concentrated slurries of poorly soluble waste and pesticides, when as a result of polymerization it is possible to change both the chemical composition and the aggregate state.
2. The objects of research were chlororganic, bromoorganic waste and pesticides with expired shelf life.

3. The gas phase of the final products was investigated by chemical and mass spectrometric methods. Their composition was determined and it was shown that the content of toxic compounds of $\mathrm{H}_{2} \mathrm{~S}$ and $\mathrm{HCl}$ is insignificant, free chlorine and dioxins are absent in the samples.

4. As a result of experimental studies, it has been established that the plasma method for the destruction and processing of waste is more environmentally friendly and economical, especially when processing highly chlorinated and hardly combustible compounds, for the thermal destruction of which a large amount of additional fuel is required. This is correlated with calculations based 
on the economic indicators of the waste and pesticides destruction process.

5. The results of studies on the processing of toxic organic and organochlorine wastes are in good agreement with the published results of the work of other authors.

\section{Acknowledgements}

This work was supported by the Ministry of Science and Education of the Republic of Kazakhstan (Program PTF/BR05236507).

\section{References}

1. A. L. Mosse, I. S. Burov. Treatment of dispersed materials in plasma reactors // Nauka i tekhnika, Minsk. - 1980. In Russian.

2. A.L. Mosse. Plasmotrons, plasma reactors and plasma furnace for processing of toxic industrial wastes // R"99 Congress Proceeding, Publishe.d EMPA. - 1999. - Vol. 2. - P. 104-109.

3. V. Brozek, M. Hrabovsky, V. Kopecky. Decomposition of polyhalogenide hydrocarbons in plasma jet generated by water stabilized plasma torch // High. Temp. Material Processes 3. - 1999. - P. 375-384.

4. V.D. Shimanovich, V.V. Azharonok, L.E. Krat'ko, N.I. Chubrik, A.L. Mosse, A.V. Gorbunov, E.M. Ermolaeva, A.N. Knak. Physical and chemical investigation of pesticide utilization process in electric arc plasma reactor // proceedings of $3^{\text {rd }}$ International Conference on plasma physics and technology. Minsk, Belarus, Sept. - 2000. - Vol. 2. - P. 616-619.

5. B. Glocker, D. Lengerken, E. Messeshmid, G. Netwig. Plasma process plant for treating hazardous waste // International Conference of Switching Arc Phenomena with International Symposium on Electrical Technologies for Environmental Protection (3-6 Sept. 1997). Lodz, Poland. - 1997. - P. 309-311.

6. G. Bonnizoni. Technologic al plasma per la distruzione dei rifiuti tossici // Milano: Quadermi FCRS 94/4. 1994. - P. 76.

7. A. Mosse, G. Kusnetzov, D. Hebecker. Conversion of liquid toxic waste by means of a plasma reactor. VDI Berichte Nr.1166. - 1995. - P. 651-657.

8. Z. Kolachinski, K. Cedrynska, L.C. Campbell. Decomposition of polychlorinated biphenyls at plasma flame temperatures // 11 International Symposium on Plasma Chemistry, London. - 1993. - Vol. 2. - P. 745-751.

9. V. Brozek, M. Hrabovsky, V. Kopecky. Study of Thermal Plasma Decomposition of polyhalogenide hydrocarbons // 13 International Symposium on Plasma Chemistry: Symposium proceedings Supplement (Beijing, China, Aug. 18-22, 1997). - 1997. - Vol. 1. - P. 1735-1739.

10. T. McAllister T. The relative efficiencies of oxidants used in plasma processing // 13 International Symposium on Plasma Chemistry: Symposium proceedings Supplement (Beijing, China, Aug. 18-22, 1997). - 1997. - Vol. 1. - P. 1780-1783.

11. Q.Y. Han, Q. Zhuang, W. Tormanen, J. Heberlein, E. Pfender . The destruction of chlorinated hydrocarbons wastes in a counter-flow plasma reactor // 11 International Symposium on Plasma Chemistry, London. - 1993. - Vol. 2. - P.758-763.

12. D. Hebecker, C. Winter. Plasmachemische vermichtung von toxischen abfallen // Chemie Ingenier Technik, 1992. - Vol. 64. - No.5. - P. 448-452.

13. A. L. Mosse, A. N. Knak, E. M. Ermolaeva, L. I. Krasovskaya. Neutralization of toxic organic wastes in threejet plasma reactor. 14-th International Symposium on Plasma Chemistry, Prague. - 1999. - Vol. 5. - P. 2483-2488.

14. R. W. Smith, R. Mutharasan, R. Knight, D. Luu, K. Malladi, J. Serino, J. Vavruska, J. Persoon, and S. Garrison, "Plasma energy recycle and conversion (PERC) of hazardous waste materials," Proc. 3rd Euro. Congr. Thermal Plasma Process (TPP-3), VDI, Aachen, Germany, 19-21 Sept. - 1994. - P. 667-674.

15. E. Ficher. Thermal destruction of chlorinated hydrocarbons // Proc. 22 Int. Symp. Combust. Seattle, Aug. 14-19, 1988. Pittsburgh, - 1988. - P. 267.

16. D.W. Park, W.B. Cha. Decomposition process of CFC-113 by thermal plasma // 13th International Symposium on Plasma Chemistry: Symposium proceedings Supplement (Beijing, China, Aug. 18-22, 1997). - 1997. - Vol. 1. - P. 1764-1769.

17. A. Cupta. Problems and progress associated with the disposal of hazardous chlorinated chemical wastes // Manag. Energy Technol. New York. - 1987. - P.75-84.

18 L.I. Krasovskaya, A.L. Mosse. Plasma-chemical processes in three-jet electric arch reactor. Minsk, ANK ITMO, $-2000 .-$ P. 169.

19. S. Ramakrishnan, R.T. Deam. PLASCON technology for waste management - an Australian experience // 11 International Symposium on Plasma Chemistry, London. - 1993. - Vol. 2. - P. 686-691.

20. A.L. Mosse, A.V. Gorbunov, E.M. Ermolaeva. Plasma energy recycle of organic and chlorinated chemical wastes: problems and prospects of detoxification. ANK ITMO. - Minsk. 2003. 